\title{
A single-dose comparison of four slow-release theophylline preparations in normal subjects
}

\author{
J. N. SHARMA \\ M.D. \\ A. Johnston \\ B.Sc. \\ A. BlacketT \\ N. R. HATHWAY \\ B.Sc., M.Sc. \\ Department of Clinical Pharmacology, St Bartholomew's Hospital, London EC1 7BE
}

\begin{abstract}
Summary
The plasma theophylline concentrations produced by 4 different slow release formulations, Theograd, Theodur, Theolair-SR and Rona-slophylline were measured over a 24-hr period in 8 healthy subjects. All 4 preparations maintained plasma levels over $12 \mathrm{hr}$ and had similar AUC values when the difference in theophylline content was taken into account. Paired saliva and plasma theophylline concentrations gave a ratio of $1: 0.38$, saliva : plasma, but with a large inter and intra individual variation.
\end{abstract}

\section{Introduction}

When administered in standard tablet formulations, theophylline has a plasma elimination half-life of about $6 \mathrm{hr}$ (Trembath and Boobis, 1979) and therefore requires 6- or 8-hourly administration to maintain adequate therapeutic plasma concentrations $(6-12 \mu \mathrm{mol} / \mathrm{l})$. Several slow release preparations have therefore been introduced which have been claimed by their manufacturers to provide rapid and sustained plasma levels for longer durations, so improving compliance and minimizing the plasma peaks and related adverse effects commonly encountered with conventional theophylline formulations. Little comparative information is available on the bioavailability of these new formulations, and the authors therefore carried out such a study on 4 slow release formulations available in the United Kingdom or the U.S.A. and at the same time they determined the plasma-salivary ratios of theophylline following these preparations.

\section{Methods}

Eight healthy volunteers ( 4 males, 4 females) aged 20-30 years took part, 2 were smokers who consumed less than 10 cigarettes/day. All subjects remained drug-free during the study period, and abstained from tea, coffee and other theophylline- containing beverages on the study days. The test formulations were administered orally fasting, food and water being allowed from $2 \mathrm{hr}$ after administration. Each of the following products was given in a single dose at weekly intervals in a randomized balanced design employing 2 Latin squares: Theograd tablet (Abbott, $350 \mathrm{mg}$ ), Theodur tablet (Key, $300 \mathrm{mg}$ ), Theolair-SR tablet (Riker, $250 \mathrm{mg}$ ), Ronaslophyllin capsule (Rona, $250 \mathrm{mg}$ ). Blood samples were collected before and at 1, 2, 3, 4, 6, 8, 12 and $24 \mathrm{hr}$ after administration. Serum and saliva were stored at $-20^{\circ} \mathrm{C}$ before estimation of theophylline by enzyme immunoassay (EMIT, Syva Corporation, Maidenhead).

The pharmacokinetic parameters, absorption rate constant $\left(\mathrm{K}_{\mathrm{a}}\right)$, apparent elimination rate constant $\left(\mathrm{K}_{\mathrm{el}}\right)$, maximum plasma concentration $\left(\mathrm{C}_{\max }\right)$ and time to peak $\left(\mathrm{t}_{\max }\right)$ were estimated graphically. Area under the curve from 0 to $24 \mathrm{hr}\left(\mathrm{AUC}_{0-24}\right)$ was calculated using the trapezoidal rule and $\mathrm{AUC}_{24-\infty}$ was determined by division of the final plasma concentration by the apparent elimination rate constant.

\section{Results}

The results are summarized in Table 1 and Fig. 1. Median peak plasma levels ranged from 3.9 to 5.5 $\mu \mathrm{g} / \mathrm{ml}$ for the 4 treatments. Half the patients recorded their highest value when using Theodur. The Friedman 2-way analysis of variance by ranks (nonparametric method) was used to analyse the plasma levels for the 4 treatments for each of the 8 time points when samples were taken. Theodur had the slowest absorption rate of the 4 preparations. At 3 and $4 \mathrm{hr}$, the plasma level was significantly lower $(P<0.01$ and 0.06 respectively) when this form was used. The time course of elimination of Theolair-SR and Rona-slophylline were similar and their plasma theophylline concentrations were significantly less at 
TABLE 1. Mean ( \pm s.e. mean) of the pharmacokinetic data of 4 slow-release theophylline preparations

\begin{tabular}{|c|c|c|c|c|}
\hline & \multicolumn{4}{|c|}{ Preparation } \\
\hline & Theograd & Theodur & Theolair-SR & Rona-slophyllin \\
\hline Theophylline content (mg) & 350 & 300 & 250 & 250 \\
\hline Half-life absorption (hr) & $1.9(0.26)$ & $2.9(0.39)$ & $2 \cdot 0(0 \cdot 32)$ & $1.6(0.25)$ \\
\hline $\begin{array}{l}\mathrm{C}_{\max } \\
\text { (median } \gamma \text { range) }(\mu \mathrm{g} / \mathrm{ml})\end{array}$ & $\begin{array}{c}3 \cdot 9 \\
(2 \cdot 3-10 \cdot 9)\end{array}$ & $\begin{array}{c}5 \cdot 5 \\
(2 \cdot 5-12 \cdot 0)\end{array}$ & $\begin{array}{c}4 \cdot 9 \\
(2 \cdot 4-11 \cdot 0)\end{array}$ & $\begin{array}{c}5 \cdot 0 \\
(2 \cdot 1-10 \cdot 0)\end{array}$ \\
\hline $\begin{array}{l}\mathrm{T}_{\max }(\mathrm{hr}) \\
\text { apparent half-life of elimination }\end{array}$ & $\begin{array}{r}5 \cdot 3(0 \cdot 6) \\
12 \cdot 0(1 \cdot 4)\end{array}$ & $\begin{array}{r}7 \cdot 1(0 \cdot 8) \\
10 \cdot 6(1 \cdot 6)\end{array}$ & $\begin{array}{r}5 \cdot 2(0 \cdot 4) \\
10 \cdot 6(1 \cdot 5)\end{array}$ & $\begin{array}{l}5 \cdot 6(0 \cdot 7) \\
7 \cdot 1(0 \cdot 4)\end{array}$ \\
\hline $\begin{array}{l}\mathrm{AUC}_{0-\infty} \\
(\mu \mathrm{g} / \mathrm{ml} / \mathrm{hr})\end{array}$ & $\begin{array}{l}102 \cdot 6 \\
(22 \cdot 1)\end{array}$ & $\begin{array}{l}111 \cdot 9 \\
(23 \cdot 3)\end{array}$ & $\begin{array}{c}85 \cdot 3 \\
(14 \cdot 6)\end{array}$ & $\begin{array}{c}75 \cdot 4 \\
(15 \cdot 0)\end{array}$ \\
\hline $\begin{array}{l}\mathrm{AUC}_{0-\infty} \\
\text { corrected to } 250 \mathrm{mg} \text { dose }\end{array}$ & $\begin{array}{c}73 \cdot 3 \\
(15 \cdot 8)\end{array}$ & $\begin{array}{c}93 \cdot 2 \\
(19 \cdot 4)\end{array}$ & $\begin{array}{l}85 \cdot 3 \\
(14 \cdot 6)\end{array}$ & $\begin{array}{c}75 \cdot 4 \\
(15 \cdot 0)\end{array}$ \\
\hline
\end{tabular}

12 and $24 \mathrm{hr}$ than those produced by Theograd and Theodur $(P<0.02$ and 0.06 respectively). The mean area under the curve (AUC) values for Theograd and Theodur were higher than those for Theolair-SR and Rona-slophylline over the 24-hr period and when extrapolated to infinity.

Paired plasma and salivary concentrations for all formulations are shown in Fig. 2. The regression line does not pass through zero. For all data, mean salivary concentration $=0.38 \times$ plasma concentration $+1.49(r=0.49, P<0.001)$.

All preparations were well tolerated and no major adverse effects were noted by any subject. Tuto subjects complained of headache and fine tremor after Theodur, and one subject of fine tremor after Rona-slophylline. No complaints were made after Theograd or Theolair-SR.

\section{Discussion}

The purpose of this study was to determine isthe pharmacokinetic properties of the 4 preparations were such that 12 hourly administration would ress in therapeutically-active plasma concentrationg. Their different theophylline contents made it diffictơf

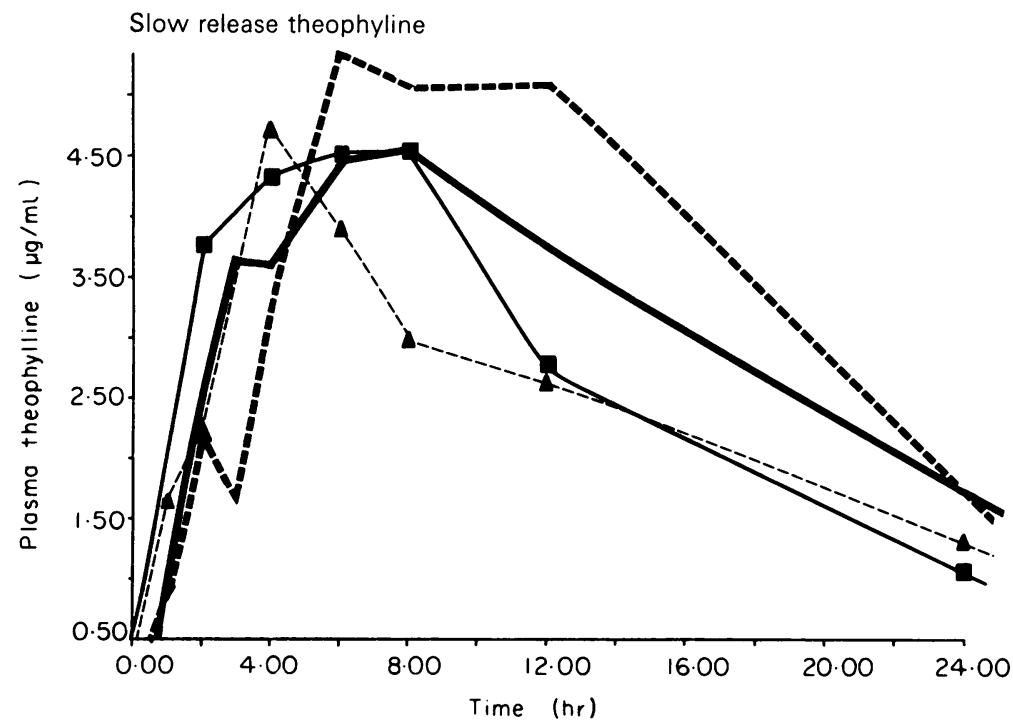

Fig. 1. Plasma theophylline time course of Theograd (- $\longrightarrow$ ), Theodur and Rona-slophylline - $)$ in 8 normal volunteers. 


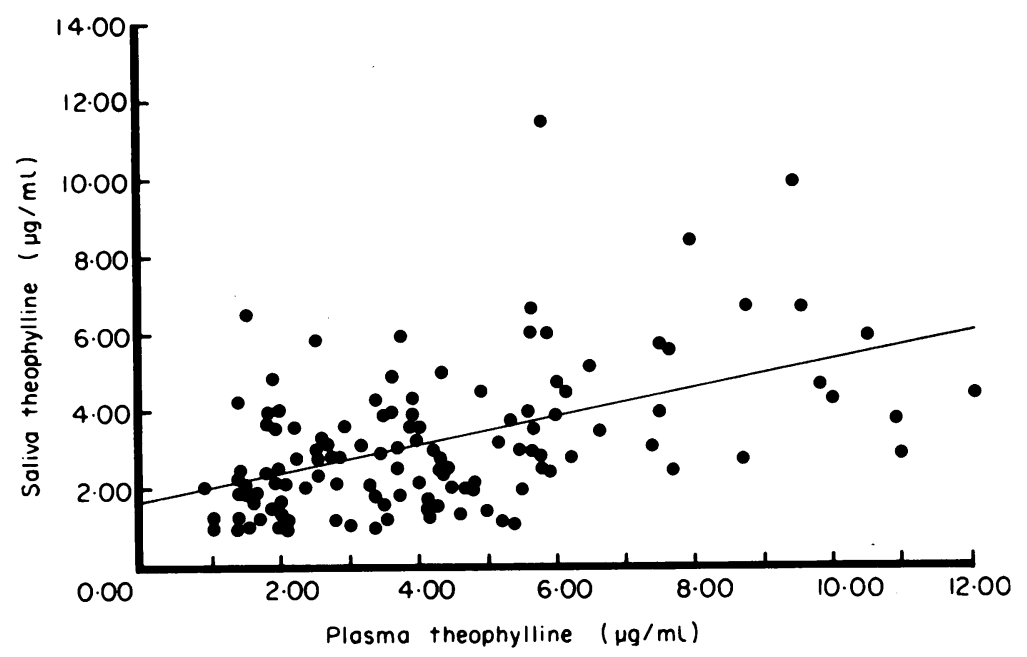

Fig. 2. Relationship between paired plasma and salivary theophylline concentrations.

to compare them directly, but it is nevertheless possible to derive certain conclusions from the observations. Theolair-SR gave the earliest mean peak plasma concentration and Theodur the latest. Theodur gave later peak plasma concentrations and sustained higher concentrations until $12 \mathrm{hr}$ compared with Theograd, even though its theophylline content was $300 \mathrm{mg}$ compared with $350 \mathrm{mg}$ in Theograd. Theodur showed the highest bioavailability and Rona-slophylline the lowest. When AUC values were recalculated on the basis of equivalent dosage, however, Theograd showed the lowest bioavailability while Theodur retained first position, although the differences were not statistically significant.

In fact, visual inspection of Fig. 1 shows that there is little to choose between the 4 preparations in maintaining plasma levels over $12 \mathrm{hr}$ and it would appear probable that 12 hourly administration should result in sustained therapeutic levels. This must be confirmed in longer term studies, however, which must include clinical assessment as well as plasma concentration estimations.

The large variation in plasma-salivary ratios confirms other observations and demonstrates that while salivary concentrations may provide a noninvasive guide to patient-compliance, they are of little value in studies of theophylline kinetics.

\section{Acknowledgment}

J.N.S. was in receipt of a Commonwealth Medical Fellowship.

\section{Reference}

Trembath, P.W. \& Boobis, S.W. (1979) Plasma theophylline levels after sustained-release aminophylline. Clinical Pharmacology and Therapeutics, 26, 654. 